\title{
İleri Kademe Arpa (Hordeum vulgare L.) Genotiplerinin Verim ve Bazı Fizyolojik Özelliklerinin Eskişehir Koşullarında Belirlenmesi
}

Ali Cevat SÖNMEZ1 9 (D) , Soner YÜKSEL ${ }^{2}$

1,2,Geçit Kuşağı Tarımsal Araştırma Enstitüsü, Ziraat Cad. No:394 Tepebaşı/ESKİ̧EHİR ${ }^{1}$ https://orcid.org/0000-0002-9818-2660, ${ }^{2}$ https://orcid.org/0000-0002-0984-0765

$\bowtie$ : alicevat.sonmez@tarimorman.gov.tr

\section{ÖZET}

Bu çalışmada, Orta Anadolu ve Geçit Bölgeleri için yatmaya dirençli, orta erkenci, hem kıraç hem de sulu şartlarda tane verimi ve kalitesi yüksek kışlık arpa çeşitlerinin geliştirilmesi amaçlanmıştır. Denemede Geçit Kuşağı Tarımsal Araştırma Enstitüsü Müdürlügü'ne ait ileri kademe 11 hat, standart olarak ta İnce-04, Larende, Tarm-92, Ünver, Özdemir-05, Erginel-90 ve Keser çeşitleri kullanılmıştır. Denemeler 2014-2015 ürün yılında tesadüf blokları deneme desenine göre 4 tekerrürlü olarak Eskişehir Merkez de Sultanönü (kıraç) ve Toprak-Su (sulu) Yerleşkelerinde yürütülmüştür. Araştırma sonuçlarına göre her iki çevrede de genotipler arası farklılıklar bu araştırmada incelenen tüm özellikler bakımından önemli $(\mathrm{P}<0.01)$ bulunmuştur. Tane verimi ve yatma değeri 'inde 9,10 ve 11 numaralı hatlar; bitki boyu 'nda Erginel-90; 1000 tane ağırlığı 'nda sulu koşullarda 1, 10, 11 numaralı hatlar ve Larende, kıraç koşullarda ise 5,8 ve 10 numaralı hatlar öne çımış̧ır. En erken başaklanan genotipler ise 1, 3 ve 9 numaralı hatlar olmuştur. Tane verimi ile yatma değeri ve başaklanma süresi parametreleri arasında negatif korelasyon önemli bulunurken, 1000 tane ağırlığı ile tane verimi arasında pozitif korelasyon önemli bulunmuştur. Sonuç olarak tüm parametrelerde üstün özellikler gösteren 10 ve 11 numaralı hatların öne çıktıkları belirlenmiştir.

\section{Araștırma Makalesi}

\section{Makale Tarihçesi \\ Geliş Tarihi $\quad: 21.02 .2019$ \\ Kabul Tarihi : :28.06.2019}

\section{Anahtar Kelimeler}

Arpa

Verim

Yatma

Erkencilik

Bin tane ağırlığ

\section{Determining of Grain Yield and Some Physiological Traits of Advanced Barley (Hordeum vulgare L.) Genotypes in Eskişehir Conditions}

\section{ABSTRACT}

In this study, it was aimed to develop higher yielding winter barley varieties with lodging resistance, medium early maturing and higher grain quality for Central Anatolia and Transitional Zone regions in both irrigated and rainfed conditions. In the trial, 11 lines from Transitional Zone Agriculture Research Institute and varieties such as İnce-04, Larende, Tarm-92, Ünver, Özdemir-05, Erginel-90 and Keser were used as standards. Trials were set up as Randomized Complete Block Design with 4 replications in 2014-2015 growing season in Eskisehir Center, Sultanönü (rainfed) and Soil-Water (irrigated) locations. According to the results of this research, the differences among genotypes were found significant $(\mathrm{P}<0.01)$ for all traits in both environments. Lines 9, 10, 11 for grain yield (GY), Erginel-90 for plant height, lines 1, 10, 11 and Larende for 1000 kernel weight in irrigated conditions, lines 5, 8 and 10 in rainfed conditions were prominent. Lines 1, 3, 9 were found as early heading genotypes. Negative correlation was found significant between grain yield and lodging score, days to heading parameters. Whereas, positive correlation was found between 1000 kernel weight and grain yield. When all the parameters were evaluated together, it is determined that the lines 10 and 11 were prominent.

\section{Research Article}

$\begin{array}{ll}\text { Article History } & \\ \text { Received } & : 21.02 .2019 \\ \text { Accepted } & : 28.06 .2019\end{array}$

\section{Keywords}

Barley

Yield

Earliness

Lodging

Thousand kernel weight

To Cite : Sönmez AC, Yüksel S 2019. İleri kademe arpa (Hordeum vulgare L.) genotiplerinin verim ve bazı fizyolojik özelliklerinin Eskişehir koşullarında belirlenmesi. KSU Tarım ve Doğa Derg 22(Ek Sayı 1): 60-68. DOI: 10.18016/ksutarimdoga.vi.530281 


\section{GİISŞ}

Arpa (Hordeum vulgare L.) ilk kültüre alınan bitkilerden birisidir (Smith ve Nesbitt, 1995). Mezopotamya ve Misir'dan gelen arpa kalıntıları, buğday kalıntılarından çok daha fazladır ve bu bulgular tarihte arpanın insan tüketimi için buğdaydan daha önemli olduğunu göstermektedir (Ceccarelli ve ark., 2007). Arpanın, ilk önceleri insan gıdası olarak kullanımı yaygınken, zamanla buğday ve pirinç'in ön plana çıkmasıyla daha çok hayvan yemi olarak kullanımı yaygınlaşmıştır (Baik ve Ullrich, 2008). Ancak son yıllarda arpa içeriğinde mevcut olan besinsel lifler, protein, B-glukan, selüloz, arabinoksilan ve zengin nişasta miktarı gıda üreticilerinin ilgisini çekmiştir (Köten ve ark., 2013).Bu kapsamda Türkiye'de \% 30 kavuzsuz arpa unu içeren ekmek üretimi 2013 yılında Ankara da gerçekleştirilmiştir (Sayim, 2018). Tüm Dünyada 145.3 milyon ton arpa üretiminin yapıldığ 2017 yılında Türkiye'de 2.42 milyon hektar alanda 7.1 milyon ton arpa üretimi yapılmış olup ortalama verim 2.93 ton ha ${ }^{-1}$ olarak gerçekleşmiştir. Bu üretimin 6.6 milyon tonu yemlik, kalan 400 bin tonu ise maltlik arpadır (Anonim, 2018). Arpa Türkiye'de tüm bölgelerde üretilmekle birlikte, çoğunlukla Orta Anadolu ve Geçit Bölgelerinde üretilmektedir. 2016 yılında bu bölgelerde 1.1 milyon hektar alanda 3.0 milyon ton arpa üretimi yapılmış olup Türkiye arpa üretiminin yaklaşık \% 45’i karşılanmıştır (Anonim, 2017). Ayrica arpa samanı da hayvan beslenmesinde çok önemli bir yere sahiptir. Tahıllar içerisinde tuza toleransı en yüksek bitkinin arpa olması (Munns ve ark., 2006) tuz oranı yüksek topraklarda tahıl üretimi yapmak isteyen çiftçilerimizin arpa ekimini tercih etmelerinin bir diğer sebebidir. Hayvancılı̆̆ın gelişmesi ve arpanın buğdaya göre daha erkenci olması nedeniyle sulu alanlarda, 1. Ürün olarak arpa ekimi artmaktadır (Öztürk ve ark., 2007). Yatma, arpa da özellikle sulu koşullarda ya da yağışın yüksek olduğu yıllarda önemli verim ve kalite kaybına sebep olan etmenlerden birisidir. Arpa üretiminde yatmaya dayanıklı çeşitlerin kullanımı yatmadan kaynaklanan verim ve kalite düşüklüğünü azaltacağı için çiftçilerin ekonomik kayıpları sinırlanacaktır. Orta Anadolu ve Geçit Bölgelerinde alınan yıllık yağışın miktarı ve aylara göre dağılımı oldukça düzensizdir. Bu nedenle bölgede düşük yağış alınan yıllarda fazla verim kaybına uğramayan, ancak uygun iklim koşulları görüldüğünde ya da sulama yapılabilen şartlarda yatmaya dayanıklı ve yüksek verim potansiyeli olan çeşitlere ihtiyaç artmaktadır. Bu çalışmada bölgemiz için sulu ve kıraç koşullarda kışlık, yatmaya dirençli, orta erkenci ve yüksek verimli çeşitlerin ıslah edilerek Türkiye'de arpa üretiminin artırılmasına destek olunması hedeflenmiştir.

\section{MATERYAL ve METOT}

$\mathrm{Bu}$ araştırma, 2014-2015 ürün yılında Geçit Kuşağ Tarımsal Araştırma Enstitüsü Müdürlüğünün (GKTAEM) Eskişehir şehir merkezinde bulunan Sultanönü ve Toprak-Su yerleşkelerindeki deneme arazilerinde iki çevrede yürütülmüştür. Sultanönü yerleşkesi yağışa dayalı (rainfed) normal koşulları temsil eden kıraç çevre olarak kabul edilirken, Toprak-Su yerleşkesi 2 sulama yapılıp daha fazla gübre verilerek yüksek verim (high input) koşullarını temsil eden sulu çevre olarak kabul edilmiştir. Uzun yıllar yıllık yağış ortalamasının $355.9 \mathrm{~mm}$ olduğu bölgede 2014-2015 ürün yılında $643.0 \mathrm{~mm}$ yağış kaydedilmiştir. Denemeler tüm sezon boyunca (özellikle haziran ayında) uzun yıllar ortalamasının (UYO) oldukça üzerinde yağış almıştır (Çizelge 1). Deneme materyali olarak kullanılan ileri kademe 11 hattın ebeveyn bilgileri ve standart olarak kullanılan çeşitlerin isimleri Çizelge 2'de verilmiştir. Denemeler tesadüf blokları deneme deseninde 4 tekerrürlü olarak kurulmuştur. Denemeler $6 \mathrm{~m}$ uzunluk ve $1.2 \mathrm{~m}$ genişlikte parsellere $20 \mathrm{~cm}$ sira arası ve 6 sira ile Ekim ayının 2. haftasında parsel ekim mibzeri kullanılarak ekilmiştir. Denemelere kıraç koşullar da $70 \mathrm{~kg} \mathrm{ha}^{-1} \mathrm{~N}$ ve $70 \mathrm{~kg} \mathrm{ha}^{-1} \mathrm{P}_{2} \mathrm{O}_{5}$ (Özdemir, 2011), sulu koşullar da ise $120 \mathrm{~kg} \mathrm{ha}^{-1} \mathrm{~N}$ ve $90 \mathrm{~kg} \mathrm{ha}^{-1} \mathrm{P}_{2} \mathrm{O}_{5}$ (Çekiç ve ark., 2008) gübre verilmiştir. Fosforlu gübrenin tamamı ve azotlu gübrenin yarısı ekimle beraber, azotlu gübrenin kalan yarısı ise ilkbaharda sapa kalkma döneminde verilmiştir. Yabancı ot yoğunluğu takip edilmiş ve geniş yapraklı yabancı otlara karşı kimyasal mücadele yapılmıştır. Sulu şartlarda denemede sulamalar ilkbaharda sapa kalkma ve başaklanma döneminde olmak üzere iki kez yağmurlama sulama olarak yapılmıştır. Hasatta parsel boyutu $1.2 \mathrm{~m}$ x $5 \mathrm{~m}$ olarak belirlenmiş, genotipler hasat olgunluğuna geldiğinde parsel biçerdöveri ile 7 Temmuz 2015 tarihinde hasat edilmiştir. Deneme de incelenen özelliklerden tane verim (TV) parsel biçerdöveri ile hasat edilen parsellerden elde edilen ürün temizlendikten sonra gram cinsinden tartılmış ve ton ha ${ }^{-1}$ cinsinden hesaplanmıştır. Bitki boyu (BB) her parselden 10 bitkinin toprak seviyesinden kılçıklar hariç en üst başakçığın ucuna kadar mesafe ölçülerek cm cinsinden kaydedilmiştir. Yatma değeri (YD) parsellerde yatma gösteren bitkilerin \% olarak oranı ve yatma açısı belirlenerek bu iki değerin çarpımından elde edilmiştir (Pask ve ark., 2012). Başaklanma süresi (BS) ekimi takip eden yılbaşından itibaren parseldeki bitkilerin yarısından fazlasının başaklarını bayrak yaprak kınından tamamen çıkardığ $\breve{1}_{1}$ tarihe kadar geçen gün sayısı olarak belirlenmiştir (Aydın ve Katkat, 1999). Bin tane ağırlığ (BTA) hasat edilen üründen alınan tanelerden dört defa yüz tane sayılıp hassas terazide tartılarak hesaplanmıştır (Williams ve ark., 1988). 
Çizelge 1. Uzun yıllar ortalaması ve 2014-15 ürün yılına ait Eskişehir ili yă̆ış verileri (mm)

\begin{tabular}{|c|c|c|c|c|c|c|c|c|c|c|c|c|c|}
\hline Yillar & Eylül & Ekim & Kasım & Aralık & Ocak & Şubat & Mart & Nisan & Mayıs & Haziran & Temmuz & Ağustos & Toplam \\
\hline UYO & 15.3 & 32.4 & 30.9 & 44.6 & 35.5 & 30.4 & 32.3 & 41.2 & 43.9 & 25.8 & 13.7 & 9.9 & 355.9 \\
\hline 2014-15 & 41.4 & 66.1 & 26.2 & 72.1 & 39 & 60.9 & 46 & 41.3 & 61.2 & 125.3 & 0 & 63.5 & 643.0 \\
\hline
\end{tabular}

(Anonim, 2015), UYO: Uzun Yıllar Ortalaması

Çizelge 2. Denemede kullanılan hatların pedigri bilgileri ve standart çeşitler

\begin{tabular}{llll}
\hline Genotip No & Pedigri & Genotip No & Pedigri \\
\hline 1 & Impact/3/Dicto-Ms/Wa1094-67//Owb753265C- & 10 & Sonata/Cwb117-5-9-5//Cw117- \\
2 & 01H/Owb763182M & 11 & $77-9-7$ \\
3 & St5822/Bülbül & 12 & Cwb117-5-9-5/ST5819//Kalayc1 \\
4 & Freya//Steptoe/Antares & 13 & Ince-04 \\
5 & Kalayc1/4/Scio/3/Dicto-Ms/Wa1094- & 14 & Tarm-92 \\
6 & 67//Owb753265C-01H/Owb 763182M & 15 & Ünver \\
7 & 97-98DH9/Kalayc1 & 16 & Özdemir-05 \\
8 & Clerine/Kalayc1 & 17 & Erginel-90 \\
9 & Cum/3/Robur/J-126//OWB753431D/ SL 3 & 18 & Keser \\
\hline
\end{tabular}

\section{BULGULAR ve TARTIŞMA}

Denemedeki genotiplere ait TV, BB, YD, BS ve BTA parametreleri kıraç ve sulu koşullar için ayrı ayrı ve birleşik varyans analiz testine tabi tutulmuştur. Araştırılan parametrelerden elde edilen kareler ortalamaları ve varyans analiz tablosu Çizelge 3 te sunulmuş̧ur. Genotiplerin ortalama değerleri Asgari Önemli Fark (AÖF) testine göre gruplandırılarak karşılaştırma yapılmış (Student, 1908) ve Çizelge $4^{\prime}$ te verilmiştir. Araştırmada incelenen parametreler aşağıda başlıklar halinde sunulmuştur.

Tane verim (TV): Ayrı ayrı yapılan varyans analizinde hem kıraç hem de sulu koşullarda genotipler arası farklılıklar önemli $\quad(\mathrm{P}<0.01)$ bulunmuştur. Birleşik analizde ise genotipler ve çevreler arası farklılıklar $(\mathrm{P}<0.01)$ seviyesinde önemli bulunurken ile genotip $\mathrm{x}$ çevre interaksiyonu $(\mathrm{P}<0.05)$ seviyesinde önemli bulunmuştur (Çizelge 3). Kıraç koşullarda TV için deneme ortalaması 3.09 ton $\mathrm{ha}^{-1}$ olurken, bu değer sulu koşullarda 4.12 ton ha-1 olmuştur. En düşük TV 1.58 ton ha ${ }^{-1}$ ile kıraç denemede Tarm-92 çeşidinden alınırken, en yüksek TV 6.34 ton ha ${ }^{-1}$ ile sulu denemeden 11 numaralı hattan alınmıştır. Genotipler incelendiğinde en yüksek TV sirasıyla 5.40 ve 5.15 ton ha ${ }^{-1}$ ile 11 ve 10 numaralı hatlardan elde edilirken, en düşük TV sirasiyla $2.73,2.22,2.50$ ve 2.40 ton ha $^{-1}$ değerler ile 7 no lu hat ve Tarm-92, Özdemir-05 ve Keser çeşitlerinden elde edilmiştir (Çizelge 4). Kalaycı ve ark. (1991)'a göre arpada TV'yi en çok etkileyen çevre etmenleri bitkinin büyüme periyodunda alınan yağışlar ve bu yağışların yıl içindeki dağılımı, sicaklık, ekim sirasinda toprakta bulunan nem miktarı, topraktaki alınabilir formda bulunan besin maddesi miktarı, ekim sıklığ ve zamanı, toprak işleme şekli, kullanılan tohumluk kalitesi ve gübrelemedir. Denemelerin 2014-2015 sezonu boyunca aldıkları yağış miktarı UYO'nun \% 81 üzerinde gerçekleşmiştir. Bu nedenle kıraç denemede su stresi fazla yaşanmamış ve sulu deneme ile aralarındaki TV farkı diğer sezonlardan daha düşük olmuştur. Ayrica genotipler hasat olgunluğuna diğer yıllarla karşılaştırıldığında yaklaşık 10 gün gecikerek ulaşmışlardır. Akar ve ark. (1999)'a göre Orta Anadolu ve Geçit Bölgelerinde yıllık ortalama yağıısın miktarının 400 mm'yi geçtiği yıllarda yatma sebebiyle arpa bitkisinde önemli verim kaybı görülmektedir. $\mathrm{Bu}$ denemede de buna paralel olarak yüksek oranda yağı̆ alı anmasına rağmen genotiplerden elde edilen TV değerleri beklenenin altında kalmıştır. Bu verim kaybının önemli sebepleri arasında yatma ve hastalıkların yoğun olarak görülmesi sayılabilir. $\mathrm{Bu}$ çalışmada elde edilen TV Sönmez ve ark. (2017)‘n Eskişehir‘de 2012-2013 ürün yılında yaptıkları çalışmada elde ettikleri 4.90 ton ha ${ }^{-1}$ ile uyumludur. Araştırmada genotip $\mathrm{x}$ çevre interaksiyonunun önemli $(\mathrm{P}<0.05)$ bulunmasinın nedeni ise özellikle 7 , 8, 9 nolu hatlar ile Erginel-90 çeşidinin çevrelere göre farklı verim düzeylerine ulaşmalarıdır. Bu bağlamda 9 numaralı hat kıraçta en üst grupta iken sulu çevrede aynı performansı gösterememiş ikinci gruba dahil olmuştur. Yine 7, 8 no lu hatlar ile Erginel-90 çeşidi sulu koşullarda kıraç koşullara nazaran daha üst verim gruplarında yer almışlardır.

Bitki boyu (BB): BB için yapılan varyans analizinde her iki çevrenin ayrı ayrı ve birlikte analizinde hem kıraç hem de sulu çevrede genotipler arası farklılıklar önemli $(\mathrm{P}<0.01)$ bulunurken, birleşik analizde de genotipler ve çevreler arası farklılıklar da önemli $(\mathrm{P}<0.01)$ bulunmuştur (Çizelge 3$)$. Kıraç çevrede BB için deneme ortalaması $84.2 \mathrm{~cm}$ olurken sulu koşullarda $110.4 \mathrm{~cm}$ olmuştur. En düşük BB $70.0 \mathrm{~cm}$ 
ile kıraç koşullarda 9 numaralı hattan alınmıştır. En yüksek bitki boyu ise $121.3 \mathrm{~cm}$ ile sulu koşullarda 8 numaralı hattan elde edilmiştir (Çizelge 4). Genotiplerin BB ortalaması incelendiğinde en yüksek BB sirasiyla $110.6 \mathrm{~cm}, 105.6 \mathrm{~cm}$ ve $105.6 \mathrm{~cm}$ ile Erginel-90 ile 7 ve 8 numaralı hatlardan elde edilirken, en düşük BB sirasıyla $83.1 \mathrm{~cm}$ ve $85.6 \mathrm{~cm}$ ile 9 numaralı hat ve Tarm-92 çeşidinden elde edilmiştir. Yüksel ve ark. (2017) yine Eskişehir de 2014-2015 yılında yaptıkları çalışmada arpada BB'yi $92.5 \mathrm{~cm}$ ile $129.5 \mathrm{~cm}$ arasında bulmuşlardır. Doğan ve ark. (2014)'a göre BB'de kalıtımın etkisi çok yüksek olsa da, çevre etkisi de önemlidir. Akdeniz ve ark. (2004)'a göre BB'de oluşan farklılıklar, bitkinin vejetatif gelişmenin yüksek olduğu Nisan ve Mayıs aylarında alınan yağış miktarıyla ilişkili olabilir. Gholipoor ve ark. (2013)'a göre modern arpa çeşitleri için en uygun BB $90-105 \mathrm{~cm}$ arasında olmasıdır. Anderson ve Reinbergs (1985)'e göre arpada bitki boyu kısalması yönünde yapılan seleksiyon yatmaya dayanıklılıkta artış sağlanmıştır. Kısa boylu çeşitler, dünyadaki tahıl yetiştiricileri tarafından, yatmayı azaltmak ve tane verimini arttırmak için geliştirilmiştir (Yu ve ark., 2010). Öztürk ve ark. (2016) Trakya bölgesinde arpada BB'nin yatmaya dayanıklılık yönünden mühim bir unsur olduğu ve BB 85-95 cm arası olan kısa veya orta boylu çeşitlerin tercih edildiği bildirmişlerdir. Kandemir (2004)'e göre arpada BB $100 \mathrm{~cm}$ den yüksek olursa yatma görüleceği söylenebilir. Denemenin yürütüldügü yll alınan yıllık yağış miktarı UYO'nun \% 81 üzerinde olmasindan dolayı vejetasyon döneminde genotiplerde su stresi yaşanmamış ve bu nedenle BB diğer sezonlara göre daha yüksek olmuştur.

Çizelge 3. Araştırılan parametrelerden elde edilen kareler ortalamaları ve varyans analiz tablosu

\begin{tabular}{|c|c|c|c|c|c|c|c|}
\hline Parametre & & Çevre & Tekerrür & Genotip & $\begin{array}{l}\text { Genotip } \mathrm{x} \\
\text { Çevre }\end{array}$ & Hata & Genel \\
\hline \multirow{5}{*}{$\begin{array}{l}\text { Tane } \\
\text { Verim }\end{array}$} & SD & & 3 & 17 & & 51 & 71 \\
\hline & Kıraç & & 3513.71 & $28466.95^{* *}$ & & 1586.59 & 8104.16 \\
\hline & Sulu & & $17022.96^{* *}$ & $36365.87^{* *}$ & & 3910.54 & 12235.58 \\
\hline & SD & 1 & 6 & 17 & 17 & 102 & 143 \\
\hline & Ortalama & $383315.77^{* *}$ & 10268.34 & $59169.39 * *$ & $5663.43^{*}$ & 2748.57 & 12779.28 \\
\hline \multirow{5}{*}{$\begin{array}{l}\text { Bitki } \\
\text { Boyu }\end{array}$} & $\mathrm{SD}$ & & 3 & 17 & & 51 & 71 \\
\hline & Kıraç & & 13.31 & $188.34^{* *}$ & & 32.18 & 68.77 \\
\hline & Sulu & & 20.83 & $281.62^{* *}$ & & 19.36 & 82.22 \\
\hline & SD & 1 & 6 & 17 & 17 & 102 & 143 \\
\hline & Ortalama & $24675.17^{* *}$ & 17.07 & $426.40^{* *}$ & 43.56 & 25.77 & 247.52 \\
\hline \multirow{5}{*}{$\begin{array}{l}\text { Yatma } \\
\text { Değeri }\end{array}$} & SD & & 3 & 17 & & 51 & 71 \\
\hline & Kıraç & & 65.03 & $1491.45^{* *}$ & & 50.34 & 373.44 \\
\hline & Sulu & & 268.6 & $2430.94^{* *}$ & & 132.34 & 632.23 \\
\hline & SD & 1 & 6 & 17 & 17 & 102 & 143 \\
\hline & Ortalama & $26487.56^{* *}$ & 124.23 & $3519.88^{* *}$ & $402.50 * *$ & 91.34 & 727.88 \\
\hline \multirow{5}{*}{$\begin{array}{l}\text { Başaklanma } \\
\text { Süresi }\end{array}$} & SD & & 3 & 17 & & 51 & 71 \\
\hline & Kıraç & & 3.5 & $38.27^{* * *}$ & & 1.56 & 10.43 \\
\hline & Sulu & & $4.72^{*}$ & $32.30^{* *}$ & & 1.17 & 8.77 \\
\hline & SD & 1 & 6 & 17 & 17 & 102 & 143 \\
\hline & Ortalama & $154.17^{* *}$ & $4.11^{* *}$ & $69.75^{* *}$ & 0.82 & 1.36 & 10.61 \\
\hline \multirow{5}{*}{$\begin{array}{l}\text { Bin } \\
\text { A } \breve{g}_{1 r l} \breve{g ̆ g}_{1}\end{array}$} & SD & & 3 & 17 & & 51 & 71 \\
\hline & Kıraç & & 3513.7 & $28467.0^{* *}$ & & 1586.6 & 8104.2 \\
\hline & Sulu & & $17023.0 * *$ & $36365.9^{* *}$ & & 3910.5 & 12235.6 \\
\hline & SD & 1 & 6 & 17 & 17 & 102 & 143 \\
\hline & Ortalama & $536.31^{* *}$ & $13.61^{* *}$ & $242.82^{* *}$ & $11.74^{* *}$ & 4.24 & 37.61 \\
\hline
\end{tabular}

**: istatistiksel olarak \% 1'de önemli; * istatistiksel olarak \% 5'te önemli; SD: Serbestlik Derecesi

Yatma değeri (YD): Tahıllar içerisinde yatma, arpa bitkisinde buğdaydan daha fazla görülür ve birçok ülkede verim kayıplarına neden olan başlıca faktörlerden biridir (Cenci, 1984). YD’yi rüzgar, düşen yağmur miktarı, toprak özellikleri, çeşit kaynaklı bitki özellikleri, ekim zamanı, ekim sıklığı, gübreleme ve bitki büyüme düzenleyici uygulamaları v.s. birçok faktörün etkilediği bilinmektedir (Berry ve ark., 2002). Nasr ve ark. (1973)'a göre yatma bitki boyu, sap kalınlığı ve başak ağırlığı ile ilişkili olup genellikle başaklanmadan sonra meydana gelmektedir. YD için yapılan her iki çevrenin ayrı ayrı ele alındığı varyans analizinde genotipler arası farklılıklar önemli $(\mathrm{P}<0.01)$ bulunmuştur. Birleşik analizde ise genotipler ve çevreler arası farklılıklar ile genotip $\mathrm{x}$ çevre interaksiyonu önemli $(\mathrm{P}<0.01)$ bulunmuştur (Çizelge 3). YD deneme ortalaması kıraçta \% 22.51 olurken, sulu koşullarda daha yüksek gerçekleşerek \% 49.75 olmuştur (Çizelge 4). Kıraç denemede en düşük YD 11 numaralı hatta \% 1 ile 
görülürken, en yüksek YD \% 84.50 ile sulu koşullarda Keser çeşidinde izlenmiştir (Çizelge 4). Genotiplerin ortalama YD incelendiğinde en yüksek YD sirasiyla \% 72.1 ve \% 75.3 ile Özdemir-05 ve Keser çeşitlerinden elde edilirken, en düşük YD sirasıyla \% 3.8, \% 9.8 ve $\% 0.9$ ile 9,10 ve 11 numaralı hatlardan elde edilmiştir (Çizelge 4). 2014-2015 sezonunda yağışların normal sezonlardan epeyce yüksek olması nedeniyle genotipler su stresi yaşamamışlardır (Çizelge 1). Bu nedenle vejetatif büyüme dönemi uzun sürmüş ve bitki boyunun normalden daha uzun olduğu görülmüştür. $\mathrm{Bu}$ nedenle yatma diğer sezonlardan daha yüksek oranda gözlemlenmiştir. YD yüksek olan genotiplerin verimleri de deneme ortalamasının altında bulunmuştur. Bu sonuç Akar ve ark. (1999)'ın bildirdiği “özellikle yıllık ortalama yağışın $400 \mathrm{~mm}$ 'den yüksek gerçekleştiği yıllarda arpa da önemli verim kayıpları yaşanmaktadır" görüşünü doğrulamaktadır. Easson ve ark. (1993) tahıllarda yüksek ekim sıklıklarının yatmayı artırdığı ve yatmanın tane doldurma döneminin başlarında olması durumunda ise tane veriminin de \% 80 'e kadar azalmasına neden olabildiğini bildirmişlerdir. Yatmaya dayanıklılı arpada bir çeşidin adaptasyonunun geliştirilmesinde yardımcı olan bir özelliktir ve yatmış bitkilerden elde edilen tanelerin çoğunlukla tane ve malt ekstresi ağırlığı daha düşüktür (Yu ve ark., 2010). Yatma sadece arpa verimini ve tane kalitesini düşürmez, aynı zamanda dolaylı olarak malt kalitesini de düşürür (Day ve Dickson, 1958). Jezowski ve ark. (2005)'a göre 6 siralı arpaları, saplarının elastikiyetlerinin 2 siralı arpalardan daha düşük ve sap çeperlerinin ise daha ince olması nedeniyle daha yüksek yatma oranı göstermektedirler. Arpada BB yatma değerini en çok etkileyen bitkisel özelliktir (Anderson ve Reinbergs, 1985). BB kısa olan bitkiler yatmaya karşı daha fazla direnç gösterirler. Dünya da tahıl ıslahçıları TV ve yatmaya direnci artırmak amacıyla daha kısa BB'ye sahip çeşitler geliştirmişlerdir (Hellewell ve ark., 2000). Yetiştirildiği bölgenin koşullarına adaptasyon sağlamış yatmaya duyarlı çeşitlerin boyunda yapılacak kısaltmalar, yatmaya daha dirençli bitkiler elde etmede etkili bir ıslah yöntemidir (Saygıll, 2012). Araştırmada YD için genotip $x$ çevre interaksiyonunun önemli $(\mathrm{p}<0.01)$ bulunmasinın nedeni ise özellikle 1, 2, 3 ve 10 numaralı genotiplerin çevrelere göre farklı YD düzeylerine ulaşmalarıdır. $\mathrm{Bu}$ bağlamda 10 numaralı hat kıraçta en alt grupta iken sulu çevrede aynı performansı gösterememiş ikinci alt gruba dahil olmuştur. Yine 1,2 ve 3 numaralı hatlar kıraç koşullarda daha üst grupta yer alırken, sulu koşullarda daha fazla YD alarak daha alt gruplarda yer almışlardır.

Başaklanma süresi (BS): BS için yapılan varyans analizinde her iki çevrenin ayrı ayrı ve birlikte analizinde hem kıraç hem de sulu çevrede genotipler arasındaki farklılıklar da önemli $\quad(\mathrm{P}<0.01)$ bulunurken, birleşik analizde de genotipler ve çevreler arası farklılıklar da önemli $(\mathrm{P}<0.01)$ bulunmuştur (Çizelge 3). Kıraç çevrede BS için deneme ortalaması 136.6 gün olurken sulu koşullarda 137.7 gün olmuştur. Kıraç çevrede en kısa BS 131.0 gün ile 9 numaralı genotipten alınırken, en uzun BS 140.8 gün ile İnce-04 çeşidinden alınmıştır. Sulu çevrede ise en kısa BS 3 numaralı hattan 133.8 gün ile alınırken, en uzun BS 143.0 gün ile yine İnce-04 çeşidinden elde edilmiştir (Çizelge 4). Genotiplerin BS ortalaması incelendiğinde en erken başaklanan genotipler sirasiyla 132.6 ve 132.5 gün ile 3 ve 9 numaralı hatlar olurken en geç başaklanan genotipler 141.9 ve 141.1 gün ile İnce-04 ve Keser olmuştur (Çizelge 4). Bu sonuçlar Akgün ve ark. (2012)'ın Konya da kıraç koşullarda yaptığı çalışmada bulduğu ortalama BS (139 gün) ile uyumludur. Aydın ve Katkat, (1999) Eskişehir de yaptıkları araştırmada BS 'yi 1992-1993 yılında 127 gün; 1993-1994 yılındaki ise 120 gün olarak tespit etmişlerdir. Bu da gösteriyor ki 2014-2015 üretim yılında denemelere düşen yağış miktarının normal sezonların epeyce üzerinde olması nedeniyle vejetatif dönem uzun sürmüş ve bitkiler normal yağışlı sezonlara göre daha geç başaklanmışlardır. Arpada erkencilik, kuraklıktan kaçınma ve hasat sonrasında ikinci ürün yem bitkisi üretimi açısından önemli bir özelliktir (Öztürk ve ark., 2014). Ancak Aydın ve Katkat (1999)'a göre erkencilik ile kuraklığa dayanım artarken çeşidin verim potansiyeli de düşmekte ve başaklanma tarihinde karşılaşılabilecek $0 \quad{ }^{\circ} \mathrm{C} \quad$ ve altındaki sıcaklıklar durumu ile de steril başak sayısı ihtimalini yükseltmektedir. Stres koşulları altında başaklanma süresinin kısaldığını bildiren bazı araştırmalar mevcuttur. Al-Menai ve ark. (2013)'a göre tuzluluk stresi, BS 'nin yaklaşık \% 8 oranında azalmasına neden olmuştur.

Bin tane ağırlığı (BTA): Her iki çevrenin ayrı ayrı ve birlikte analizinde hem kıraç hem de sulu çevrede genotipler arası farklılıklar önemli $\quad(\mathrm{P}<0.01)$ bulunurken, birleşik analizde genotip $\mathrm{x}$ çevre interaksiyonu önemli $(\mathrm{P}<0.01)$ bulunmuştur (Çizelge 3). Kıraç çevrede BTA için deneme ortalaması $43.7 \mathrm{~g}$ olurken sulu koşullarda bu değer $47.6 \mathrm{~g}$ olmuştur. En düşük BTA sırasıyla $30.5 \mathrm{~g}$ ve $34.4 \mathrm{~g}$ ile hem kıraç hem de sulu koşullarda bu denemedeki tek 6 siralı standart çeşit olan Erginel-90 çeşidinden alınmıştır. Diğer genotiplerde ise en düşük BTA sırasıyla $40.2 \mathrm{~g}$, $39.1 \mathrm{~g}, 37.8 \mathrm{~g}, 38.6 \mathrm{~g}$ ve $39.8 \mathrm{~g}$ ile $3,4,7$ numaralı hatlar ile Tarm-92 ve Özdemir-05 çeşitlerinden alınmıştır. En yüksek BTA ise kıraç ta sırasıyla 49.5 $\mathrm{g}, 52.2 \mathrm{~g}$ ve $49.9 \mathrm{~g}$ ile 5,8 ve 10 numaralı hatlardan elde edilmiştir (Çizelge 4). 
Çizelge 4. Araştırmada incelenen özelliklerin çevrelere ve ortalamalara göre değerlerinin karşılaştırılması, AÖF testi ve değişim katsayısı değerleri

\begin{tabular}{|c|c|c|c|c|c|c|c|c|c|c|c|c|c|c|c|}
\hline \multirow[b]{2}{*}{ Genotip No } & \multicolumn{3}{|c|}{ Tane Verim (ton ha-1) } & \multicolumn{3}{|c|}{ Bitki Boyu $(\mathrm{cm})$} & \multicolumn{3}{|c|}{ Yatma Değeri (\%) } & \multicolumn{3}{|c|}{ Başaklanma süresi (gün) } & \multicolumn{3}{|c|}{ Bin Tane Ağırlığı $\quad$ g) } \\
\hline & Kıraç & Sulu & Ortalama & Kıraç & Sulu & Ortalama & Kıraç. & Sulu & Ortalama & Kiraç. & Sulu & Ortalama & Kıraç & Sulu & Ortalama \\
\hline 1 & $3.62 \mathrm{bcd}$ & $4.15 \mathrm{de}$ & $3.88 \mathrm{CD}$ & $81.3 \mathrm{~d}-\mathrm{g}$ & $105.0 \mathrm{e}$ & $93.1 \mathrm{HIJ}$ & $14.0 \mathrm{efg}$ & $22.5 i j$ & $18.3 \mathrm{HI}$ & $132.8 \mathrm{~g}-\mathrm{i}$ & $135.0 \mathrm{gh}$ & $133.9 \mathrm{HI}$ & $49.2 \mathrm{~b}$ & $55.2 a$ & $52.2 \mathrm{~A}$ \\
\hline 2 & $3.06 \mathrm{~d}-\mathrm{g}$ & $3.76 \mathrm{efg}$ & $3.40 \mathrm{DE}$ & $85.0 \mathrm{~b}-\mathrm{f}$ & $112.5 \mathrm{~cd}$ & $98.8 \mathrm{C}-\mathrm{G}$ & $25.3 \mathrm{~d}$ & $47.0 f-h$ & $36.1 \mathrm{EF}$ & $133.0 \mathrm{gh}$ & $134.5 \mathrm{~h}$ & $133.8 \mathrm{IJ}$ & $43.6 \mathrm{~cd}$ & $47.4 \mathrm{fg}$ & $45.5 \mathrm{CD}$ \\
\hline 3 & $3.81 \mathrm{bc}$ & 4.17 def & $3.99 \mathrm{C}$ & $88.8 \mathrm{bcd}$ & $116.3 \mathrm{a}-d$ & $102.5 \mathrm{BCD}$ & $15.0 \mathrm{efg}$ & $35.8 \mathrm{hi}$ & $25.4 \mathrm{GH}$ & $131.5 \mathrm{hi}$ & $133.8 h$ & $132.6 \mathrm{JK}$ & $40.2 \mathrm{ef}$ & $48.8 \mathrm{def}$ & $44.5 \mathrm{CD}$ \\
\hline 4 & $2.66 \mathrm{gh}$ & $3.38 \mathrm{fgh}$ & $3.02 \mathrm{EF}$ & 87.5 b-e & $116.3 \mathrm{a}-d$ & 101.9 BCD & $22.0 \mathrm{de}$ & $60.0 \mathrm{~d}-g$ & $41.0 \mathrm{DE}$ & $137.8 \mathrm{~cd}$ & $139.8 c-f$ & $138.8 \mathrm{EF}$ & $39.1 \mathrm{f}$ & $41.2 j k$ & $40.1 \mathrm{~F}$ \\
\hline 5 & $3.16 \mathrm{~d}-\mathrm{g}$ & 3.86 ef & $3.51 \mathrm{CDE}$ & $82.5 \mathrm{c}^{-} \mathrm{g}$ & $113.8 c d$ & $98.1 \mathrm{D}-\mathrm{H}$ & $11.8 \mathrm{fg}$ & $44.3 g h$ & $28.0 \mathrm{FG}$ & $137.3 \mathrm{de}$ & $140.3 b^{-e}$ & $138.8 \mathrm{EF}$ & $49.5 \mathrm{ab}$ & $52.0 b c$ & $50.7 \mathrm{AB}$ \\
\hline 7 & $1.99 \mathrm{ij}$ & $3.47 \mathrm{fgh}$ & $2.73 \mathrm{FG}$ & $91.3 \mathrm{~b}$ & $120.0 a b$ & $105.6 \mathrm{AB}$ & $22.0 \mathrm{de}$ & $70.3 a^{-} d$ & $46.1 \mathrm{CD}$ & $138.0 \mathrm{~b}-\mathrm{d}$ & $140.5 \mathrm{bcd}$ & 139.3 DE & $37.8 \mathrm{f}$ & $40.6 k$ & $39.2 \mathrm{~F}$ \\
\hline 8 & $2.79 \mathrm{~g}$ & 3.99 ef & $3.39 \mathrm{DE}$ & $90.0 \mathrm{bc}$ & $121.3 \mathrm{a}$ & $105.6 \mathrm{AB}$ & $16.3 \mathrm{~d}-\mathrm{g}$ & $53.3 e^{-g}$ & $34.8 \mathrm{EFG}$ & $139.8 \mathrm{ab}$ & $140.5 \mathrm{bcd}$ & $140.1 \mathrm{BCD}$ & $52.2 \mathrm{a}$ & $52.1 b c$ & $52.1 \mathrm{~A}$ \\
\hline 9 & $4.05 \mathrm{ab}$ & $4.97 \mathrm{bcd}$ & $4.51 \mathrm{~B}$ & $70.0 \mathrm{~h}$ & $96.3 f$ & $83.1 \mathrm{~L}$ & $1.3 \mathrm{~h}$ & $6.5 j k$ & $3.8 \mathrm{~J}$ & $131.0 \mathrm{i}$ & $134.0 \mathrm{~h}$ & $132.5 \mathrm{~K}$ & $43.0 \mathrm{~d}$ & $47.5 \mathrm{efg}$ & $45.2 \mathrm{CD}$ \\
\hline 10 & $4.58 \mathrm{a}$ & $5.71 a b$ & $5.15 \mathrm{~A}$ & $90.0 \mathrm{bc}$ & $117.5 a b c$ & $103.8 \mathrm{BC}$ & $1.5 \mathrm{~h}$ & $18.0 j$ & $9.8 \mathrm{IJ}$ & $138.3 \mathrm{~b}-\mathrm{d}$ & $140.5 \mathrm{bcd}$ & 139.4 CDE & $49.9 \mathrm{ab}$ & $52.7 a b c$ & $51.3 \mathrm{~A}$ \\
\hline 11 & $4.46 \mathrm{a}$ & $6.34 a$ & $5.40 \mathrm{~A}$ & $82.5 \mathrm{c}^{-} \mathrm{g}$ & $105.0 e$ & 93.8 G-J & $1.0 \mathrm{~h}$ & $1.0 \mathrm{k}$ & $0.9 \mathrm{~J}$ & $133.8 \mathrm{fg}$ & $136.3 \mathrm{~g}$ & $135.0 \mathrm{H}$ & $49.3 \mathrm{~b}$ & $53.2 a b c$ & $51.3 \mathrm{~A}$ \\
\hline İnce-04 & 3.49 b-e & $3.78 \mathrm{efg}$ & $3.63 \mathrm{CD}$ & $85.0 \mathrm{~b}-\mathrm{f}$ & $115.0 \mathrm{bcd}$ & $100.0 \mathrm{CDE}$ & $38.0 \mathrm{c}$ & 66.0 b-e & $52.0 \mathrm{C}$ & $140.8 \mathrm{a}$ & $143.0 \mathrm{a}$ & $141.9 \mathrm{~A}$ & $44.2 \mathrm{~cd}$ & 44.6 ghi & $44.4 \mathrm{CD}$ \\
\hline Larende & $3.36 \mathrm{c}-\mathrm{f}$ & $4.17 \mathrm{def}$ & $3.77 \mathrm{CD}$ & $83.8 \mathrm{~b}-\mathrm{f}$ & $105.0 e$ & 94.4 F-J & $15.3 \mathrm{~d}-\mathrm{g}$ & $56.3 d-g$ & $35.8 \mathrm{EF}$ & $139.3 \mathrm{a}^{-c} \mathrm{c}$ & $141.0 b c$ & 140.1 BCE & $49.2 \mathrm{~b}$ & $54.0 a b$ & $51.6 \mathrm{~A}$ \\
\hline Ünver & $3.10 \mathrm{~d}-\mathrm{g}$ & 4.12 def & $3.61 \mathrm{CD}$ & $78.8 \mathrm{fg}$ & 100.0 ef & $89.4 \mathrm{JK}$ & $22.0 \mathrm{de}$ & $62.8 c-f$ & $42.4 \mathrm{DE}$ & $137.8 \mathrm{~cd}$ & 139.3 def & $138.5 \mathrm{EF}$ & $41.9 \mathrm{de}$ & 50.5 cde & $46.2 \mathrm{C}$ \\
\hline Özdemir-05 & $2.19 \mathrm{hi}$ & $2.82 h$ & $2.50 \mathrm{FG}$ & $82.5 c^{-g}$ & $116.3 a^{-}-d$ & $99.4 \mathrm{C}-\mathrm{F}$ & $62.0 \mathrm{a}$ & $82.3 a b$ & $72.1 \mathrm{AB}$ & 135.5 ef & $138.3 f$ & $136.9 \mathrm{G}$ & $39.8 \mathrm{ef}$ & $44.8 \mathrm{gh}$ & $42.3 \mathrm{E}$ \\
\hline Erginel-90 & $2.80 \mathrm{fg}$ & $5.10 b c$ & $3.95 \mathrm{C}$ & $101.3 \mathrm{a}$ & $120.0 a b$ & $110.6 \mathrm{~A}$ & $18.0 \mathrm{def}$ & $52.8 \mathrm{efg}$ & $35.4 \mathrm{EF}$ & $137.3 \mathrm{de}$ & 138.8 ef & 138.0 FG & $30.5 \mathrm{~g}$ & 34.41 & $32.5 \mathrm{G}$ \\
\hline Keser & $1.90 \mathrm{ij}$ & $2.90 \mathrm{gh}$ & $2.40 \mathrm{G}$ & $81.3 \mathrm{~d}-\mathrm{g}$ & 100.0 ef & $90.6 \mathrm{IJK}$ & $66.0 \mathrm{a}$ & $84.5 \mathrm{a}$ & $75.3 \mathrm{~A}$ & $140.5 \mathrm{a}$ & $141.8 a b$ & $141.1 \mathrm{AB}$ & $43.0 \mathrm{~d}$ & $44.3 \mathrm{hij}$ & $43.6 \mathrm{DE}$ \\
\hline Ortalama & $3.09 B$ & $4.12 \mathrm{~A}$ & 3.60 & $84.2 B$ & $110.4 \mathrm{~A}$ & 97.3 & $22.5 B$ & $49.8 A$ & 36.1 & $136.6 B$ & $138.7 \mathrm{~A}$ & 137.7 & $43.7 \mathrm{~B}$ & $47.6 A$ & 46.7 \\
\hline $\mathrm{DK}_{(\%)}$ & 12.91 & 15.19 & 14.56 & 6.69 & 3.99 & 5.22 & 31.32 & 23.11 & 26.39 & 1.77 & 0.78 & 0.85 & 4.42 & 4.57 & 4.51 \\
\hline $\begin{array}{l}\text { AÖF } \\
\text { genotip }(0.05)\end{array}$ & 0.57 & 0.89 & 0.52 & 8.05 & 6.25 & 5.04 & 10.07 & 16.33 & 9.48 & 0.91 & 1.53 & 1.16 & 2.75 & 3.09 & 2.05 \\
\hline
\end{tabular}

DK: Değişim Katsayısı; AÖF: Asgari Önemli Fark 
Genotiplerin BTA ortalaması incelendiğinde en düşük BTA $32.5 \mathrm{~g}$ ile Erginel-90 çeşidinden alınırken, en yüksek BTA ise sırasiyla $52.2 \mathrm{~g}, 50.7 \mathrm{~g}, 52.1 \mathrm{~g}, 51.3 \mathrm{~g}$, $51,3 \mathrm{~g}$ ve $51.6 \mathrm{~g}$ değerler ile $1,5,8,10,11$ numaralı hatlar ile Larende çeşidinden elde edilmiştir. $\mathrm{Bu}$ çalışmada elde edilen BTA sonuçları yapılan birçok çalışma ile uyumlu bulunmuştur (Aydoğan ve ark., 2011; İmamoğlu ve ark., 2016). BTA tanenin irilik, dolgunluk, cllızlık durumu ve yanı sira tane verimi hakkında da fikir vermesi bakımından önemli bir kalite unsurudur (Öztürk ve ark., 2007). Engin (1989)'e göre tane iriliği ile malt ekstrakt oranı arasındaki korelasyon pozitif ve önemlidir. Atlı ve ark. (1989) maltlık arpada BTA'nın 40 gramdan daha yüksek olması gerektiğini belirtmişlerdir.

Özellikler arası korelasyonlar: Araştırmada özellikler arası ilişkiler incelenmiş olup korelasyon tablosu Çizelge 5 te sunulmuştur. Buna göre gerek kıraç gerekse sulu koşullarda TV ile YD ve BS parametreleri arasindaki korelasyon negatif ve önemli bulunurken, TV ile BTA arasındaki korelasyon pozitif ve önemli bulunmuştur. Yine YD ile BTA arasındaki korelasyon olumlu ve önemli bulunurken, YD ile BS arasındaki korelasyon ise negatif ve önemli bulunmuştur. Gerek kıraç gerekse sulu koşullarda BS'nin TV ile arasında negatif ve önemli bir ilişki saptanırken, YD ile arasındaki korelasyonun olumlu olduğu saptanmıştır (Çizelge 5). $\mathrm{Bu}$ araştırmaya paralel olarak Easson ve ark. (1993)'a göre de TV ile YD arasında negatif korelasyon vardır. Yine Kıran (1999) yaptığı araştırmada, TV ile BTA ve YD arasında önemli bir ilişki bulduğunu belirtmiştir.

Çizelge 5. Denemede araştırılan özellikler arası korelasyon tablosu

\begin{tabular}{|c|c|c|c|c|c|c|c|c|}
\hline & & TV & YD & BB & $\mathrm{BS}$ & BTA & & \multirow{7}{*}{ 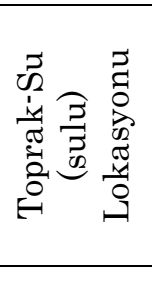 } \\
\hline \multirow{6}{*}{ 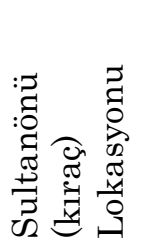 } & TV & & $-0.689 * *$ & $0.151^{\text {öd }}$ & $-0.280^{*}$ & $0.426^{* *}$ & TV & \\
\hline & YD & $-0.613^{* *}$ & & $0.132^{\text {öd }}$ & $0.560^{* * *}$ & $-0.452^{* *}$ & YD & \\
\hline & $\mathrm{BB}$ & $0.058^{\text {od }}$ & $-0.028^{\text {odd }}$ & & 0.096 öd & $-0.131^{\text {od }}$ & BB & \\
\hline & BS & $-0.421^{* *}$ & $0.376^{* *}$ & $0.195^{\text {öd }}$ & & -0.193 öd & BS & \\
\hline & BTA & $0.511^{* *}$ & $-0.323^{* *}$ & $-0.163^{\text {od }}$ & $0.009^{\text {od }}$ & & BTA & \\
\hline & & TV & YD & BB & BS & BTA & & \\
\hline
\end{tabular}

**: istatistiksel olarak \% 1'de önemli; * istatistiksel olarak \% 5’te önemli; öd: Önemli değil

TV:Tane verim; YD:Yatma değeri; BB:Bitki boyu; BS: Başaklanma süresi; BTA: Bin tane ağırlığı

\section{SONUÇ}

Araştırma sonuçlarma göre her iki çevrede de genotipler arası farklılıklar bu araştırmada incelenen tüm unsurlarda önemli $(\mathrm{P}<0.01)$ bulunmuştur. Özellikle YD'nin TV'yi önemli oranda etkilediği görülmüş ve yatma oranı düşük genotiplerin TV değerleri yüksek bulunmuştur. Kıraç ve sulu koşulların ortalama değerlerine göre TV ve YD parametrelerinde 9, 10, 11 numaralı hatlar, BB 'de Erginel-90, BTA unsurunda 1, 5, 8, 10 ve 11 numaralı hatlar ile Larende çeşidi öne çıkmıştır. En erken başak çıkartan genotipler ise 1, 3 ve 9 numaralı hatlar olmuştur. TV ile YD ve BS parametreleri arasında korelasyon negatif ve önemli bulunurken, BTA ile korelasyon pozitif ve önemli bulunmuştur. Tüm parametreleri bir arada değerlendirildiğinde 10 ve 11 numaralı hatların her iki çevrede de verim, erkencilik ve yatmaya dayanıklılık özellikleri yönünden öne çıktığg tespit edilmiş ve tescil ettirmek amaciyla Tohumluk Tescil ve Sertifikasyon Merkezi Müdürlüğüne teklif edilmiştir.

\section{KAYNAKLAR}

Akar T, Avcı M, Düşünceli F, Tosun H, Ozan N, Sipahi H 1999. Orta Anadolu ve geçit bölgelerinde arpa tarımının sorunları ve çözüm yolları. Orta Anadolu'da Hububat Tarımının Sorunları ve Çözüm Yolları Sempozyumu, 8-11 Haziran, Konya. Akdeniz H, Keskin B, Yılmaz İ 2004. Bazı arpa çeşitlerinin verim ve verim unsurları ile bazı kalite özellikleri üzerinde bir araştırma. Yüzüncü Yıl Üniversitesi, Tarım Bilimleri Dergisi, 14(2): 119125.

Akgün N, Topal A, Akçura M 2012. Evaluation of Central Anatolian barley landraces for crop improvement. Romanian Agricultural Research, 29: 87-93.

Al-Menaie HS, Mahgoub HS, Al-Ragam O, Al-Dosery N, Mathew M, Suresh N 2013. Performance and Yield Components of Forage Barley Grown Under Harsh Environmental Conditions of Kuwait. In Advance in Barley Sciences (pp. 367-374).

Anderson MK, Reinbergs E 1985. Barley breeding pp. 231-268 in Barley (D.C. Rasmusson ed.), Agronomy Monograph No. 26, American Society for Agronomy, Madison, Wisconsin, USA.

Anonim 2015. Geçit Kuşağı Tarımsal Araştırma Enstitüsü Müdürlüğü, İklim Kayıtları, Eskişehir

Anonim 2017. TUIK istatistikleri. www.tuik.gov.tr (Erişim tarihi: 23.07.2017)

Anonim 2018. http://www.tmo.gov.tr/Upload/ Document/hububatsektorraporu2017.pdf

Atlı A, Koçak N, Köksel H, Tuncer T 1989. Yemlik ve Maltlık arpada kalite kriterleri ve arpa islah programlarında kalite değerlendirmesi. Arpa-Malt Seminerleri, Konya 23-27.

Aydın M, Katkat AV 1999. Water Consumption and Growth of Some Barley Genotypes Under Eskişehir Conditions. Turkish Journal of 
Agriculture and Forestry, 23 (EK4):797-802.

Aydoğan S, Şahin M, Akçacık AG, Ayrancı, R 2011. Konya Koşullarına Uygun Yüksek Verimli ve Kaliteli Arpa Genotiplerinin Belirlenmesi. Selçuk Tarım Bilimleri Dergisi, 25(1): 10-16.

Baik BK, Ullrich SE 2008. Barley for food: characteristics, improvement, and renewed interest. Journal of cereal science, 48: 233-242.

Berry PM, Spink JH, Sylvester-Bradley R, Pickett A, Sterling M, Baker C, Cameron N 2002. Lodging control through variety choice and management. In Proceedings of the 8th Home-Grown Cereals Association R \& D Conference on Cereals and Oilseeds, pages (pp. 7-1).

Ceccarelli S, Grando S, Capettini F Baum M 2007. Barley breeding for sustainable production. International Center for Agricultural Research in the Dry Areas (ICARDA), p 17 Aleppo, SyriaCenci CA, Grando S, Ceccarelli S 1984. Culm anatomy in barley (Hordeum vulgare). Canadian Journal of Botany 62(10): 2023 - 2027.

Çekiç C, Savaşlı E, Dayığlu R, Önder O, Karaduman Y, Avcıoğlu R 2008. Ekmeklik Buğdayda (Triticum aestivum L.) Ekim Zamanı ve Sıklığı ile Kalite Kriterleri Arasındaki İlişkilerin Belirlenmesi. Ülkesel Tahıl Sempozyumu, 2-5 Haziran, Konya.

Day AD, Dickson AD 1958. Effect of artificial lodging on grain and malt quality of fall-sown irrigated barley. Crop Sci 50:338-340

Doğan Y, Kendal E, Karahan T, Çiftçi V 2014. Diyarbakır Koşullarında Bazı Arpa Genotiplerinde Verim ve Bazı Kalite Özelliklerinin Belirlenmesi. JAFAG, 31(2): 31-40.

Easson DL, White EM, Pickles SJ 1993. The effects of weather, seed rate and cultivar on lodging and yield in winter wheat. The Journal of Agricultural Science, 121(2), 145-156.

Engin A 1989. Biralık arpalarda önemli kalite özellikleri ve bunların malt kalitesi üzerine etkileri. Arpa-Malt Semineri, 30 Mayıs - 1 Haziran, s 38-41, Konya

Gholipoor M, Rohani A, Torani S 2013. Optimization of traits to increasing barley grain yield using an artificial neural network. International Journal of Plant Production 7(1): ISSN: 1735-6814 (Print), 1735-8043 (Online)

Hellewell KB, Rasmusson DC, Gallo-Meagher M 2000. Enhancing yield of semidwarf barley. Crop Science, 40(2): 352-358.

İmamoğlu A, Pelit S, Sarı N, Büyükkileci C, Yıldız Ö 2016. Ege Bölgesi Sahil Kuşağına Uyumlu Arpa (Hordeum vulgare L.) Çeşit ve Genotiplerinin Verim ve Bazı Kalite Özelliklerinin Belirlenmesi. Tarla Bitkileri Merkez Araştırma Enstitüsü Dergisi, 25 (özel sayı-1): 141-145.

Jezowski S, Surma M, Adamski T, Krajewski P 2005. Genetic analysis of morphological and physical stem characteristics determining lodging resistance in two-and six-rowed barley (Hordeum vulgare L.) lines. International agrophysics, 2005 (19): 299-303

Kalaycı M, Siirt S, Aydın M, Özbek K 1991. Yıllık Çalışma Raporu. Geçit Kuşağı Tarımsal Araştırma Enstitüsü. Eskişehir.

Kandemir N 2004. Tokat-Kazova şartlarına uygun maltlık arpa çeşitlerinin belirlenmesi. Gaziosmanpaşa Üniversitesi Ziraat Fakültesi Dergisi, 2004, 21 (2): 94-100

Kıran AK 1999. Bazı arpa (Hordeum vulgare L.) genetik kaynakları materyalinin karakterizasyonu. Anadolu J. of AARI, 9(2): 72-90.

Köten M, Ünsal S, Atlı A 2013. Arpanın İnsan Gidası Olarak Değerlendirilmesi. Türk Tarım-Gıda Bilim ve Teknoloji Dergisi, 1, 51-55.

Munns R, James RA, Läuchli A 2006. Approaches to increasing the salt tolerance of wheat and other cereals. Journal of experimental botany, Vol. 57, No: 5, pp. 1025-1043 Nasr HG, Shands HL, Forsberg RA 1973. Correlation between kernals pulmpness, lodging and other agronomic characteristic in six- rowed barley crosses. Crop Sci. 13 (4): 399 - 401.

Özdemir S 2011. Farklı Lokasyonlarda Ekilen Buğday Çeşitlerinin Optimum Ekim Sıklığının Belirlenmesi. ESOGU Fen Bilimleri Enst., Tarla Bit. ABD, Yüksek Lisans Tezi, $96 \mathrm{~s}$.

Öztürk İ, Avcs R, Kahraman T 2007. Trakya bölgesinde yetiştirilen bazı arpa (Hordeum vulgare L) çeşitlerinin verim ve verim unsurları ile bazı kalite özelliklerinin belirlenmesi. U. Ü. Ziraat Fakültesi Dergisi, 21 (1): 59-68

Öztürk İ, Avcs R, Kaya R, Vulchev D, Popova T, Valcheva D, Dimova D 2014. Bazı Arpa (Hordeum vulgare L.) Genotiplerinin Edirne koşullarında Verim ve Bazı Tarımsal Özelliklerinin İncelenmesi. Tarla Bitkileri Merkez Araştırma Enstitüsü Dergisi, 23 (2): 41-48

Öztürk İ, Avcı R, Tülek A, Kahraman T, Tuna B 2016. Bazı Arpa (Hordeum vulgare L) Genotiplerinin Trakya Bölgesinde Verim ve Agronomik Özelliklerinin Araştırılması. Tarla Bitkileri Merkez Araştırma Enstitüsü Dergisi, 25 (1): 26-34.

Pask AJD, Pietragalla J, Mullan DM, Reynolds MP 2012. Physiological breeding II: a field guide to wheat phenotyping., Cimmyt, $131 \mathrm{~s}$.

Saygilı I 2012. Arpada kisa boyluluk genleri kazandırılan bazı yakın izogenik hatların çeşitli tarımsal ve bitkisel özelliklerinin belirlenmesi. Gaziosmanpaşa Ünv. Fen Bilimleri Enst., Tarla Bit. ABD. Yüksek Lisans Tezi, $27 \mathrm{~s}$.

Sayim İ, Ergun N, Aydoğan S 2018. Kavuzsuz Arpa. http://www.ankarahalkekmek.com.tr/Dosyalar/ 62805911779.pdf. (Erişim Tarihi:20.11.2018)

Smith BD, Nesbitt M 1995. The emergence of agriculture (p. 231). New York: Scient. American Library. 
Sönmez AC, Yüksel S, Belen S, Çakmak M, .Akın A 2017. Kıraç Koşullarda Orta Anadolu ve Geçit Bölgeleri İçin Geliştirilen Bazı Arpa (Hordeum vulgare L.) Hat ve Çeşitlerinin Tane Verim ve Bazı Kalite Unsurlarının İncelenmesi. KSU Doğa Bilimleri Dergisi, 20 (Özel Sayl): 258-262

Student 1908. The Probable Error of a Mean. Biometrica.Volume 6, Issue 1(Mar., 1908), 1-25

Williams P, El-Haramein FJ, Nakkoul H, Rihawi S
1988. Crop quality evaluation methods and guidelines. Crop quality evaluation methods and guidelines, (14, Ed. 2.).

Yüksel S, İkincikarakaya SÜ, Sönmez AC, Belen S, Yıldırım Y 2017. Eskişehir Ekolojik Koşullarında Bazı Arpa Hat ve Ceşitlerinin Verim ve Verim Öğeleri Üzerine Bir Araştırma. KSU Doğa Bilimleri Dergisi 20 (Özel Sayı): 252-257. 